Using the Internet as a Pleasure Travel Planning Tool: An Examination of the Sociodemographic and Behavioral Characteristics among Internet Users and Nonusers

\author{
Mark A. Bonn \\ Florida State University \\ H. Leslie Furr \\ Georgia Southern University \\ Alex M. Susskind \\ Cornell University
}

September 22, 1998

\begin{abstract}
Author Note
The authors contributed equally to the preparation of this manuscript; their names are presented in alphabetical order. Correspondence concerning this manuscript should be addressed to Mark A. Bonn.

Mark A. Bonn, Ph.D., is an associate professor in the Department of Hospitality Administration, Florida State University (4100 University Center Building B, Tallahassee, FL 32306-2541; e-mail: mbonn@gamet.acns.fsu.edu).

H. Leslie Furr, Ph.D., is an associate professor and program director of Hotel and Restaurant Management at Georgia Southern University (P.O. Box 8034, Statesboro, GA 30460-8034; e-mail: lfurr@gsvms2.ee.gasou.edu).

Alex M. Susskind, Ph.D., is an assistant professor in the School of Hotel Administration at Cornell University (242 Statler Hall, Ithaca, NY 14853-6902; e-mail: ams76@ comell.edu).
\end{abstract}




\begin{abstract}
A critical prerequisite for the formulation of effective travel marketing strategies in the next decade must include an understanding of the influence exerted through the Internet. The increasing presence of the Internet as an instrument for advertising travel destinations and travel-related services highlights its importance as a factor in travelers' decision-making processes. This exploratory investigation examined travelers who requested on-line information about a potential vacation destination using the Internet. Results of this investigation suggest that Internet "users," when compared with “nonusers," are more educated, have higher household incomes, use commercial lodging accommodations while traveling, tend to travel by air, and spend more money on travel-related expenses on a per diem basis. Implications for target marketing strategies designed for travel destination areas, services, and facilities are discussed.
\end{abstract}

Keywords: Internet; travel; destination marketing; consumer behavior; and marketing strategy. 


\title{
Using the Internet as a Pleasure Travel Planning Tool: An Examination of the Sociodemographic and Behavioral Characteristics among Internet Users and Nonusers
}

\begin{abstract}
The Internet
Individuals use the Internet for a wide variety of purposes. December (1996) identifies three interdependent functions of the Internet: (a) communication between individuals, (b) interaction for leisure and/or education, and (c) information transfer among individuals. These functions may be achieved through (a) asynchronous communication, such as electronic mail, electronic bulletin boards, and World Wide Web (WWW) pages, to which data are posted and retrieved by users at distant points in time or (b) synchronous communication, such as chat rooms or conference call features, at which time the users are simultaneously connected and are able to exchange information while "connected" to one another (December, 1996; Morris \& Ogan, 1996; Walle, 1996; Williams, Bascombe, Brenner, \& Green, 1996). The Internet can be used in one or more of the following configurations: (a) one-to-one interchange, (b) one-to-many interchange, (c) many-to-one interchange, or (d) many-to-many interchange (Morris \& Ogan, 1996).

The Internet continues to gain widespread acceptance in our society as a communication medium and information source (Newhagen \& Rafaeli, 1996). The current estimate of 25 million Internet users (Morris \& Ogan, 1996) is expected to expand to between 200 and 500 million users by the turn of the century (Bauwens, 1995). Internet connections can be found with increasing frequency in educational institutions, governmental institutions, commercial operations, and in private homes.

Today, it is virtually impossible to avoid hearing about the Internet (Walle, 1996) and its utility as an immense resource base. However, mere knowledge of the Internet's existence does not necessarily lead to utilization. Use of the Internet requires access to a personal computer, an on-line service, and a motivation to seek information from a computerized format.
\end{abstract}




\section{Implications of the Internet for Consumer Marketing}

As technology usage continues to influence the business environment, notable changes are surfacing in business interaction (Peterson, Balasubramanian, \& Bronnenberg, 1997). It is now becoming impossible for businesses to exclude the Internet from their marketing mix. While the four P's of marketing (product, place, price, and promotion) remain a stable part of existing marketing processes (Kotler, 1991), hospitality marketers have correctly expanded the marketing mix to include other important hospitality-relevant factors such as "people," "packaging," "programming," and "partnership" (Morrison, 1989, p. 37). At this point, the mix should be further extended to specifically include issues of technology, such as the Internet. This implies that traditional marketing efforts need to remain consumer driven but should continue to become more technologically based.

\section{The Internet as a Marketing Tool}

Each Internet application can contribute a unique educational and/or entertainment opportunity to the user depending on his or her intended purpose. The Inter net is most likely to be useful in asynchronous interchange because most current travel and tourism businesses' commercial usage revolves around the solicitation and provision of services and information. For example, a cruise line operator or travel agent may support a WWW page or bulletin board where their cruise-based information is made available to Internet users seeking information about cruises. The WWW page or bulletin board may contain information that is very general in nature, company specific, and/or industry specific. The available information can guide the Internet user toward a search for additional travel and tourism-related information, which may result in a travel service purchase. In many cases WWW sites are linked to other sites with similar or complementary postings. This approach to the procurement of travel and tourismrelated information is relatively new and growing in popularity (Walle, 1996).

However, it is not expected that the Internet will completely replace traditional consumer-based travel and tourism exchange (Peterson et al., 1997), leaving direct, non-computer-mediated, person-toperson interaction intact for those consumers who prefer more traditional purchase options. In fact, it is 
more likely that the Internet will help augment existing travel and tourism services, through the provision of additional options for efficient information exchange and on-line purchases. New on-line services continue to gain acceptance by consumers nearly as quickly as they are introduced. EXPEDIA, a new travel marketing information resource, reported 100 million dollars in on-line travel sales during the first 6 months of business in 1997 (Murphy, 1997). The question remains whether or not Internet-based information is sufficiently organized by travel service purveyors to effectively sustain those consumers seeking travel and tourism information via the Internet (Kasavana, Knutson, \& Polonowski, 1998).

\section{Marketing Channels}

In particular, the Internet provides an opportunity for travel and tourism service providers to intermix traditional marketing channels (i.e., distribution, transaction, and communication), which were previously considered independent processes (Peterson et al., 1997). A single interaction on the Internet can provide product information, a means for payment and product exchange, and distribution, whereas more traditional interaction frequently separates these functions. Although each marketing channel is anticipated to be affected by the increasing use of the Internet, communication and transaction channels are most likely to have the greatest influence on purchase-based behavior (Jacoby, Hoyer, \& Brief, 1992; Peterson et al., 1997). This suggests that consumers will be able to easily gather information about products and services on the Internet and use the Internet to make on-line purchases. The actual distribution of goods and services, however, is less likely to be affected by the Internet unless the goods or services are digitally based, such as electronic airline tickets or other digital assets (Peterson et al., 1997).

\section{Product and Service Characteristics}

It is important to note that product and service characteristics also will heavily influence the degree to which the Internet can be effectively used as a marketing resource for travel and tourism purposes. Three main characteristics of products and services are likely to influence Internet usage for 
both information seeking and making on-line purchases (Peterson et al., 1997): (a) the cost and frequency of purchase, (b) value proposition, and (c) the degree of differentiation. First, it is likely that inexpensive items such as gasoline (low involvement) would be purchased more frequently than expensive items such as automobiles or cruise-based vacations (high involvement). Therefore, on the basis of these differences in the level of involvement in the purchase process, it could be anticipated that consumers would be more interested in receiving greater amounts of information about high-involvement items to aid in their decision-making process (Jacoby et al., 1992). Second, whether goods and services are tangible (value proposition) also influences the utility of the Internet as a marketing tool. If a product is tangible (i.e., automobile), consumers may be interested in gathering information about the product (i.e., pictures, specific features, cost, and options), but prior to making a purchase, the consumer would expect to "sample" the product (i.e., test-drive an automobile), making it unlikely that an on-line purchase would be made. Conversely, with intangible items (i.e., a vacation package), consumers would be interested in receiving detailed information but would not anticipate a sample. In this case, the Internet can be used to provide considerable detail about the product or service and provide the Internet user with options to make on-line purchases, adding convenience to the purchase process by combining the traditional communication and transaction channels. Finally, whether or not a product or service is easily differentiated will determine the extent to which the Internet is useful for information gathering and making on-line purchases. Products with low levels of differentiation and no apparent sustainable competitive advantage will be more difficult to successfully market on the Internet, because price competition would remain fierce (e.g., airline tickets for travel in the continental United States or gasoline). On the other hand, unique vacation destinations (e.g., Disney World) have features that could be effectively differentiated and easily offered through on-line services.

In sum, travel and tourism-related products and services appear to be well suited to Internet marketing because of their distinctive high-priced, high- involvement, well-differentiated characteristics. Current Internet research suggests that a variety of individuals are attracted to using the Internet as an informational gathering tool (Schonland \& Williams, 1996; Walle, 1996). It is important to note, 
however, that despite the general popularity of the Internet, to date, Internet usage tends to remain related to specific sex, education, income, and occupational characteristics (Furr \& Bonn, 1998; Schonland \& Williams, 1996). As identified by Kasavana et al. (1998), "The Internet as a marketing tool is still a relatively new concept, however, the ability to accurately measure the audience [emphasis added] is still in its infancy" (p. 37). Therefore, it is useful to further classify travel and tourism consumers' demographic profiles in terms of their propensity to use the Internet. A classification procedure such as this will help identify those consumers who are flexible in the selection of communication and transaction channels (Jacoby et al., 1992; Peterson et al., 1997) for travel and tourism-related purchases. It can also provide information to suppliers and service providers working with the Internet to efficiently communicate a strategic travel-sales approach to offer accommodations and services to their targeted customers in terms of marketing channel usage and product and service characteristics (Furr \& Bonn, 1998; Kasavana et al., 1998; Morrison, Pearce, Moscardo, Nadkami, \& O’Leary, 1996; Peterson et al., 1997; Walle, 1996).

\section{Research Questions}

The goal of this exploratory investigation was to examine the specific sociodemographic and behavioral characteristics of tourists and travelers who use the Internet (users), compared with those who do not use the Internet (nonusers), to gather information about tourism and travel. To identify the root characteristics of Internet users versus nonusers, the following sociodemographic-based and behaviorally based variables were examined: (a) sex, (b) age, (c) education, (d) income, (e) number of children, (f) accommodation type, (g) travel mode, (h) trip purpose, (i) daily expenditures while traveling, and (j) length of stay while traveling.

\section{Sociodemographic Characteristics}

Prior research has indicated that demographic variables generally tend to be poor descriptors of behaviorally based outcomes and suggest that basic demographic characteristics yield less useful 
information about markets than other consumer characteristics (Andereck \& Caldwell, 1994). However, when looking at traditional marketing processes, demographic categories, such as educational level attained, provide researchers with easily measurable aspects of individuals but rarely provide travel and tourism researchers with information on which to base strategic marketing decisions. In this case, our goal is to uncover a general propensity to use the Internet among pleasure travelers. We have narrowed our investigation to pleasure travelers to determine if specific sociodemographic features are able to provide insight into travel and tourism-related behavior. Specifically, travel and tourism purchases, when considered in the context of a vacation, are typically high-involvement, high-cost, well-differentiated items (Peterson et al., 1997), suggesting that individuals consistently using the Internet for travel and tourism purchases are likely to share basic sociodemographic features in terms of sex, age, education, income, and having children. These individuals are likely to have the greatest economic impact on travel and tourism activities. If these individuals can be reached more effectively via the Internet, it is beneficial to those marketing travel and tourism products and services.

Research Question 1: Does one's propensity to use the Internet to gather information about potential vacation destinations vary as a function of sex?

Research Question 2: Does one's propensity to use the Internet to gather information about potential vacation destinations vary as a function of the participant's age?

Research Question 3: Does one's propensity to use the Internet to gather information about potential vacation destinations vary as a function of the participant's level of education?

Research Question 4: Does one's propensity to use the Internet to gather information about potential vacation destinations vary as a function of the participant's income?

Research Question 5: Does one's propensity to use the Internet to gather information about potential vacation destinations vary as a function of the participant's number of children under the age of 13 ? 


\section{Behavioral Characteristics}

If consumers' propensity to use the Internet for travel-related purchases can be associated with specific sociodemographic characteristics, it also would be useful to determine which specific consumption behavior patterns are associated with Internet usage. This suggests that once pleasure travelers have selected their vacation destinations and activities, their reported consumption behavior should be related to specific product and service decision-making processes (Jacoby et al., 1992), such as Internet usage.

Research Question 6: Does one's propensity to use the Internet for information about potential vacation destinations vary as a function of the lodging accommodations used?

Research Question 7: Does one's propensity to use the Internet to gather information about vacation destinations vary as function of the participant's mode of travel?

Research Question 8: Does one's propensity to use the Internet to gather information about potential vacation destinations vary as a function of the participant's trip purpose?

Research Question 9: Does one's propensity to use the Internet to gather information about potential vacation destinations vary as a function of the participant's daily expenditures while traveling?

Research Question 10: Does one's propensity to use the Internet to gather information about potential vacation destinations vary as a function of the participant's trip length?

\section{Method}

\section{Participants}

During 1996, professional surveyors contacted 6,724 travelers to be interviewed concerning a recent trip to Florida vacation destinations. Of those contacted, $90 \%(n=6,052)$ completed the personal interviews as presented. Using a randomized day/site/time sampling frame, area visitors were asked to complete a 10-minute interview. A total of 5,319 participants indicated that their primary trip purpose was 
for pleasure, whereas the remaining 733 indicated their trip purpose was for business or some other nonleisure purpose and were excluded from further analyses. ${ }^{1}$

\section{Procedure}

During the scheduled interview, the research participants were asked to respond to items on a questionnaire, which addressed specific issues concerning their recent trip. Items included primary destinations visited while traveling, types of accommodations used during the trip, activities, demographic variables, and Internet usage.

Participants' Internet usage was categorized by their responses to several Internet-related questions included in the survey. Participants were first asked if "they currently use or have a personal computer at home" and "if yes, do you use an on-line computer service?" Participants responding yes to both questions were used in further analyses $(n=1,364)$. The selected participants were then asked if they use the Internet to request information about a potential vacation destination. The participants were categorized on the basis of their self-reported propensity to use the Internet to gather information about a potential vacation destination as either Internet users or nonusers.

\section{Analyses}

To answer the 10 research questions posited above, two statistical methods were employed. First, to answer Research Questions 1 through 4, and 6 through 8, global chi-square tests of sample population variances were applied to the categorical and nominal data (i.e., sex, age, education, income, accommodation type, travel mode, and trip purpose). Chi-square analyses facilitated the separation of participants by user and nonuser status, and examined their sociodemographic and behavioral characteristics based on that categorization. Next, to answer Research Questions 5, 9, and 10, one-way analysis of variance (ANOVA) was applied to the data (i.e., the number of children under the age of 13, daily expenditures while traveling, and the length of stay on the trip) in terms of the participants' status as Internet users or nonusers to obtain travel and tourism information. This technique was selected to 
facilitate the individual assessment of each univariate effect, based on dependent variables that provided continuous data. Chi-square and ANOVA techniques were chosen for use in this exploratory investigation to aid in the classification of Internet users and nonusers, rather than predict specific demographic or behavioral outcomes. $^{2}$

\section{Results}

\section{Demographic Characteristics}

The initial chi-square analyses were conducted to determine differences among the Internet user and nonuser groups' sex, age, education, and income. In response to Research Question 1, the participants' sex revealed a nonsignificant chi-square, $\chi^{2}(1)=\bullet 194, p=.66$, suggesting that the propensity to use the Internet to gather travel-related information is not different among men and women (see Table 1). Analyses of Research Questions 2 and 3 revealed significant results among the categories of age and education by user and nonuser classification, $\chi^{2}(3)=13.67, p=.003$, and $\chi^{2}(3)=11.39, p=$ .01 , for age and level of education, respectively, suggesting that the levels of age and education as measured are not independent of the participants' reported Internet usage behavior. The analysis of the family income data (Research Question 4) suggests that visitors with higher family incomes are more

likely to use the Internet as a travel information source than nonusers, $\chi^{2}(1)=47.21, p<.001$. The test of Research Question 5 (with ANOVA) revealed that those respondents who traveled with more children under the age of 13 were more likely to be Internet users than those who traveled with fewer children, $F=$ $5.28, p=.02, \eta^{2}=.004($ see Table 2$)$.

\section{Behavioral Characteristics}

The tests of Research Questions 6 and 7 (see Table 3) revealed that participants who stayed overnight in a commercial lodging establishment and traveled by air were more likely to use the Internet compared with their counterparts, $\chi^{2}(1)=8.18, p-.004$, and $\chi^{2}(1)=14.08, p<.001$, for accommodation 
type and travel mode, respectively. The test of Research Question 8 revealed that the participants' trip purpose (i.e., outdoor vacation, sporting events) is likely to influence one's propensity to use the Internet for travel-related information, $\chi^{2}(10)=28.35, p=.002$ (see Table 2).

The last of analyses (using ANOVA) to test Research Questions 9 and 10 revealed that Internet users spent significantly more money per day, on the average, than the nonusers, $F=6.20, p=.013, \eta^{2}=$ .005 (see Table 4), and Internet usage was not influenced by the number of nights spent at the travel destination, $F=.456, p=.50, \eta^{2}<.001$ (see Table 5).

\section{Discussion}

This investigation represents an initial attempt to classify pleasure travelers in terms of their propensity to use the Internet and other relevant sociodemographic and behavioral characteristics. Overall, our findings suggest that the majority of the respondents are likely to use the Internet for travel and tourism purposes. More than $70 \%$ of the respondents in each demographic category indicated that they would be willing to seek travel-related information on the Internet. However, the natural "breaks" in the data offer some practical insight into the respondents' demographic and behavioral characteristics.

From a demographic perspective, sex does not appear to have a substantial impact on this sample's propensity to gather information about potential vacation destinations. In terms of age and education, younger people or people with higher educational levels were slightly more likely to use the Internet as a travel information-gathering tool. However, it is interesting to note that $77 \%$ of the respondents who had access to the requisite Internet tools reported they would use the Internet regardless of their age or educational level. As a whole, the findings suggest that those under the age of 45 , with a college education, an income of more than $\$ 50,000$, and with children are more likely to use the Internet for travel and tourism purposes. In addition, these respondents indicated that they spend more while traveling; use commercial lodging accommodations; travel by air; and in decreasing frequency reported their primary trip purpose as visiting with friends and relatives, attending theme parks, seeking rest and relaxation activities, and engaging in local excursions. In this case, the length of the trip in question was 
not significantly related to Internet usage behavior. This noted profile is not trivial with regard to providing and marketing travel and tourism services to pleasure travelers. The noted differences among Internet users and nonusers are most likely due to the fact that the Internet users tend to have more disposable income and travel more frequently. Therefore, they represent a specific target group, despite researchers' assertions that demographic variables are not useful discriminators for segmentation purposes.

Most destination areas attempt to attract travelers who are more likely to have the greatest economic impact (Uysal, Fesenmaier, \& O’Leary, 1994), and in this case respondents who reportedly would use the Internet to gather travel- and tourism-related information clearly spend more money on travel and tourism products and services than nonusers. Behavioral characteristics such as original purpose for trip, daily expenditures while traveling, and travel mode appear to be practical discriminators among users and nonusers and should be helpful in the design of economically motivated strategic plans. In this case, reported family income represents one of many characteristics, which are likely to highlight the greatest economic impact of pleasure travelers.

\section{Limitations}

Several limitations with regard to the conduct of this investigation should be addressed. First, to determine the Internet usage pattern of the respondents, several dichotomous questions were presented to qualify or disqualify the respondents (such as owning a computer and subscribing to an on-line service). This classification excluded respondents from the user category if they did not own a computer. However, it is possible that some respondents use a computer at work or a library and have access to on-line services without a subscription. This presents two problems specifically: (a) Those who use on-line services without owning a computer are likely to have lower incomes and may have skewed the income data reported, and (b) those who own a computer but are able to use on-line services without a subscription are likely to be younger (e.g., students) and differ from the older respondents both demographically and behaviorally. These limitations should be addressed in future research to better 
describe a full range of Internet users. Second, we reported a $90 \%$ response rate in the investigation. This introduces the issue of nonresponse bias to our research. It is important to equally understand respondents and nonrespondents from a sample population. It is quite possible that those who opted not to respond to the survey were characteristically different from those who did. Sutton (1989) asserts that a complete examination of both respondents and nonrespondents leads to a better description of research phenomena. Future investigations of this type should attempt to better explain nonrespondents in field-based survey research. Finally, this investigation examined travelers to Florida destinations only. Although the sample size is sufficiently large to draw statistical conclusions from the analyses, the geographic specificity limits the generalizability of the results. Even though Florida represents the largest tourist destination in the United States, travel and tourism are growing both nationally and internationally. Future investigations should look beyond Florida destinations to offer a greater understanding of consumers' travel and tourism behavior and the influence the Internet holds.

\section{Problems On-Line?}

The use of the Internet as a marketing resource is in its infancy (Kasavana et al., 1998). The Internet potentially offers a rich, dynamic environment for the exchange of information and resources. However, potential Internet users face several limitations when they approach the Internet as a travel and tourism information source, which should be mentioned. First, there are no firm "rules" governing the credibility of Internet postings and information exchange. A "surfer" is not protected from locating false or misleading information and has a limited means of determining a posting's face validity (Williams et al., 1996). Second, the Internet and its related technologies are not necessarily fluid in terms of software, hardware, WWW site location, and citation addresses (Williams et al., 1996). As a result of the variable state of technological capabilities, some Internet users are unable to access certain data types, and they may be faced with software/hardware compatibility issues. Third, numerous WWW sites and Internet offerings are often neglected, which affects how frequently information on the site is updated. Fourth, security is always an issue when using the Internet to gather information or make purchases. When 
contacting a site on the Internet, you are, in effect, supplying the web-site provider with your Internet identification in order to browse. Any user choosing to make a purchase on the Internet must usually provide some form of payment information (i.e., credit card number) to complete the transaction. Therefore, for Internet users to gain confidence in consistently acquiring travel and tourism information and services through the Internet, both providers and users need to pay close attention to the issues of credibility, technology, accuracy, and security (Williams et al., 1996).

\section{Implications and Conclusion}

The most practical characteristics that distinguish Internet users from nonusers were family income, respondent age, overnight accommodation type, travel mode, and trip purpose. This suggests that the respondents who reported they are most likely to use the Internet to seek travel- and tourism-related information can be profiled as people who are college educated, earn more than $\$ 50,000$ per household per year, spend more per day while traveling, travel by air, and prefer to stay in commercial lodging establishments while in the travel destination area. These findings indicate that there may be utility in offering customized promotional materials on the Internet that tie directly into individuals' intended primary trip purpose. This is likely to lead to a greater identification of travel segment consumers who will provide the greatest economic impact when traveling to their pleasure destinations. In particular, Internet users who travel by air and use commercial lodging facilities are likely to spend more money during their trips. While at their destinations, these travelers tend to be "restricted" to their destination area and rely on local restaurants, shops, and merchants to provide their food and activities. With that in mind, marketing professionals should target these travelers using the Internet to offer vacation packages to them at their desired vacation destinations.

Today's hospitality and tourism marketing researcher needs to concentrate as much on choosing the promotional media as developing an appropriate message when dealing with a value-conscious traveler. The well-educated and more affluent traveler requires accurate, in-depth, and timely information about potential destination areas. This investigation revealed that the Internet can be a viable means for 
distributing travel-related information. Destination marketing organizations must begin to more realistically interpret how particular levels of operational efficiency associated with their marketing and promotion budgets could positively affect the future of promoting travel destinations. In other words, using targeted marketing strategies that use the Internet as an additional promotional medium may better attract visitors who tend to have a greater economic impact than visitors who do not use the Internet to plan their pleasure trips. 


\section{NOTES}

1. This research was conducted on the basis of a larger Florida traveler/visitor's survey. The goal of the project was to assess Florida pleasure travelers' vacation-based behavior and preferences for use in travel and tourism development to attract pleasure travelers to Florida destinations. The sample consisted of Florida travelers during a visit to Tampa. Participants' primary vacation destination was assessed and revealed that Tampa, Orlando, Miami, Palm Beach, and Naples represented the majority of the respondents' primary vacation destinations. The survey and research materials used in this investigation are proprietary and can only be obtained through the Tampa/Hillsborough Convention and Visitors Association, Inc.

2. Because the distribution of the categorical variables in most cases was broad, to form our "profiles," we collapsed several of the categories to increase the interpretability of the data. This narrowed the number of categories but broadened our ability to classify respondents as users or nonusers. For example, to base our conclusion about the age profile from Table 1, we combined the age categories of $<34$ and 34-44. Together, they now represent $55 \%$ of the total respondent base $(n=744)$ who indicated they would use the Internet, whereas only $14 \%$ in those same two age-groups $(n=188)$ indicated they would not. Although this technique is based on a series of qualitative judgments, it provides additional insight for future profiling efforts. 
Table 1. Chi-Square Analysis of Demographic Characteristics of Internet Users Who Would Seek Travel Information on the Internet.

\begin{tabular}{|c|c|c|c|c|c|c|c|}
\hline \multirow[b]{3}{*}{ Variable } & \multicolumn{4}{|c|}{$\begin{array}{l}\text { umber and \% of Respondents Who } \\
\text { Would (or would not) Seek Travel } \\
\text { Information on the Internet }\end{array}$} & \multirow[b]{3}{*}{$\chi^{2}$} & \multirow[b]{3}{*}{$d f$} & \multirow[b]{3}{*}{$p$} \\
\hline & \multicolumn{2}{|c|}{ Yes } & \multicolumn{2}{|c|}{ No } & & & \\
\hline & $n$ & $\%$ & $n$ & $\%$ & & & \\
\hline $\operatorname{Sex}(N=1,364)$ & & & & & .194 & 1 & .660 \\
\hline Male & 577 & 77.4 & 168 & 22.6 & & & \\
\hline Female & 484 & 78.4 & 133 & 21.6 & & & \\
\hline Age $(N=1,364)$ & & & & & 13.671 & 3 & .003 \\
\hline$\leq 34$ & 340 & 76.1 & 107 & 23.9 & & & \\
\hline $35-44$ & 404 & 83.3 & 81 & 16.7 & & & \\
\hline $45-54$ & 230 & 76.2 & 72 & 23.8 & & & \\
\hline 55 or older & 77 & 70.0 & 33 & 30.0 & & & \\
\hline Education $(N=1,364)$ & & & & & 11.396 & 3 & .010 \\
\hline $\begin{array}{l}\text { High school graduate, } \\
\text { vocational-technical, } \\
\text { or less }\end{array}$ & 111 & 72.5 & 42 & 27.5 & & & \\
\hline Some college & 198 & 73.6 & 71 & 26.4 & & & \\
\hline College & 537 & 79.0 & 143 & 21.0 & & & \\
\hline Postgraduate & 202 & 84.2 & 38 & 15.8 & & & \\
\hline Income $(N=1,364)$ & & & & & 47.213 & 2 & .000 \\
\hline$\$ 49,999$ or less & 317 & 68.3 & 147 & 31.7 & & & \\
\hline$\$ 50,000-\$ 74,999$ & 228 & 82.0 & 50 & 18.0 & & & \\
\hline$\$ 75,000$ or more & 255 & 88.9 & 32 & 11.1 & & & \\
\hline
\end{tabular}


Table 2. One-Way ANOVA Comparing Respondents' Number of Children to Internet Information Users or Nonusers $(N=1,370)$

\begin{tabular}{|c|c|c|c|c|c|c|}
\hline \multirow[b]{2}{*}{ Number of Children } & \multirow[b]{2}{*}{$n$} & \multirow[b]{2}{*}{$M$} & \multirow[b]{2}{*}{$S D$} & \multirow[b]{2}{*}{$S E$} & \multicolumn{2}{|c|}{$5 \%$ Confidence Interva } \\
\hline & & & & & $\begin{array}{l}\text { Lower } \\
\text { Bound }\end{array}$ & $\begin{array}{l}\text { Upper } \\
\text { Bound }\end{array}$ \\
\hline \multicolumn{7}{|l|}{ Request information } \\
\hline Yes & 1,063 & .76 & 1.29 & 3.95E-02 & .68 & .84 \\
\hline No & 301 & .57 & .96 & $5.54 \mathrm{E}-02$ & .47 & .68 \\
\hline Total & 1,364 & .72 & 1.22 & 3.32E-02 & .65 & .78 \\
\hline $\begin{array}{l}\text { Number of Children } \\
\text { Under } 13 \text { Years of Age }\end{array}$ & \multicolumn{5}{|c|}{ Number of Children } & $p$ \\
\hline Between groups & & 7.897 & 1 & 7.897 & 5.282 & .022 \\
\hline Within groups & & $2,036.434$ & 1362 & 1.495 & & \\
\hline Total & & $2,044.331$ & 1363 & & & \\
\hline
\end{tabular}

Note: $\mathrm{ANOVA}=$ analysis of variance. 
Table 3. Chi-Square Analysis of Economic and Travel-Related Characteristics of Internet Users

Who Would Seek Travel Information on the Internet.

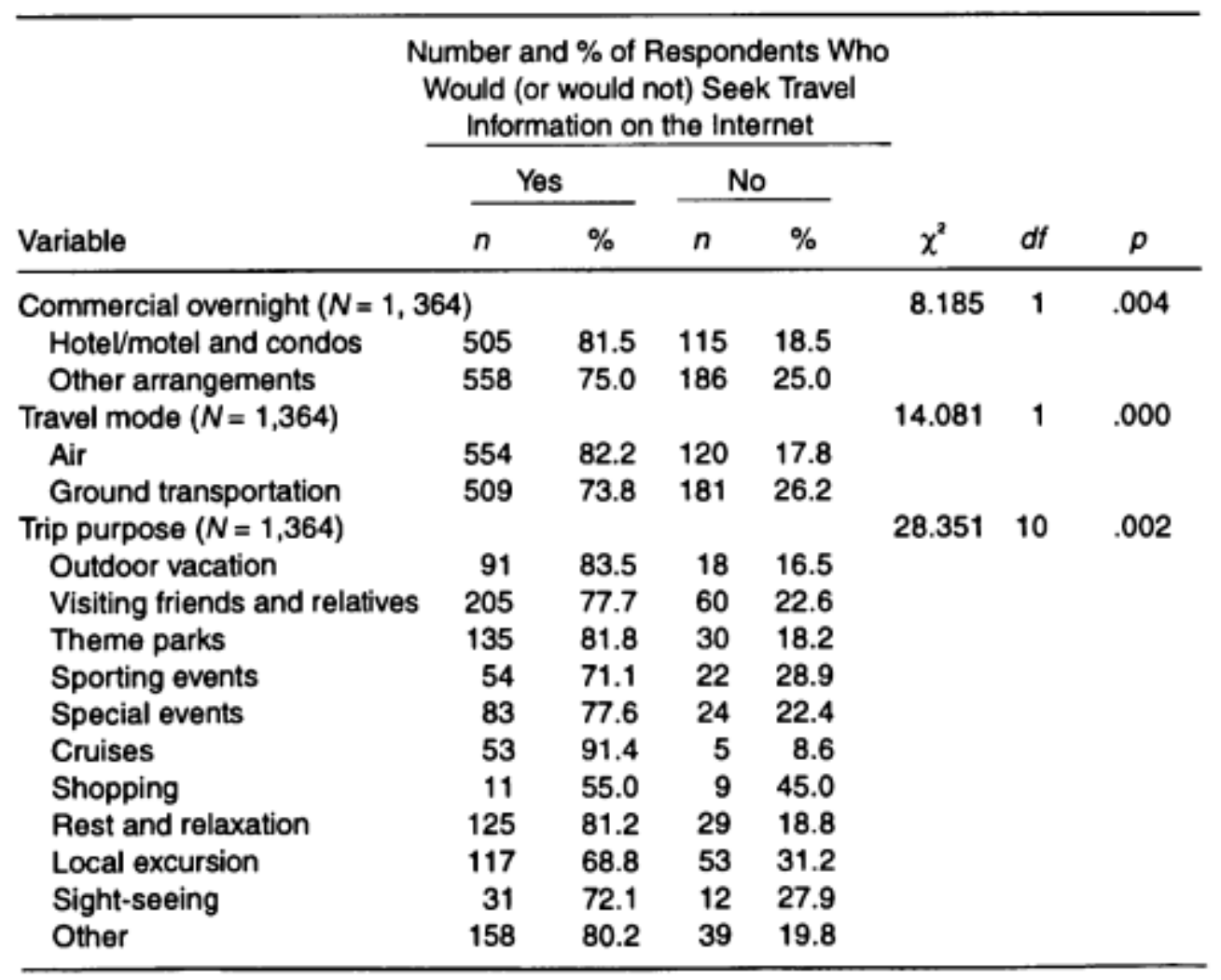


Table 4. One-Way ANOVA Comparing Respondents' Total Dally Expenditures to Internet Information Users or Nonusers $(N=1,370)$

\begin{tabular}{|c|c|c|c|c|c|c|}
\hline \multirow[b]{2}{*}{$\begin{array}{l}\text { Average Expenditures } \\
\text { per Day }\end{array}$} & \multirow[b]{2}{*}{$n$} & \multirow[b]{2}{*}{$M$} & \multirow[b]{2}{*}{$S D$} & \multirow[b]{2}{*}{$S E$} & \multicolumn{2}{|c|}{$95 \%$ Confidence Interva } \\
\hline & & & & & $\begin{array}{l}\text { Lower } \\
\text { Bound }\end{array}$ & $\begin{array}{l}\text { Upper } \\
\text { Bound }\end{array}$ \\
\hline \multicolumn{7}{|l|}{ Request information } \\
\hline Yes & 1,063 & $\$ 248.22 \$$ & $\$ 256.30$ & 7.86 & 232.80 & 263.65 \\
\hline No & 301 & $\$ 207.76$ & $\$ 220.51$ & 12.71 & 182.74 & 232.77 \\
\hline Total & 1,364 & $\$ 239.29$ \$ & $\$ 249.33$ & 6.75 & 226.05 & 252.54 \\
\hline \multicolumn{2}{|c|}{ Total Daily Expenditures } & Im of Squares & is $d f$ & Mean Square & $F$ & $p$ \\
\hline Between groups & & $384,145.0$ & 1 & $384,145.0$ & 6.203 & .013 \\
\hline Within groups & & $8.4 E+07$ & 1362 & $61,930.366$ & & \\
\hline Total & & $8.5 E+07$ & 1363 & & & \\
\hline
\end{tabular}

Note: $\mathbf{A N O V A}=$ analysis of variance. 
Table 5. One-Way ANOVA Comparing Respondents' Length of Stay to Internet Information Users or Nonusers $(N=1,370)$

\begin{tabular}{|c|c|c|c|c|c|c|}
\hline \multirow[b]{2}{*}{ Number of Nights Stay } & \multirow[b]{2}{*}{$n$} & \multirow[b]{2}{*}{$M$} & \multirow[b]{2}{*}{$S D$} & \multirow[b]{2}{*}{$S E$} & \multicolumn{2}{|c|}{$95 \%$ Confidence Interval } \\
\hline & & & & & $\begin{array}{l}\text { Lower } \\
\text { Bound }\end{array}$ & $\begin{array}{l}\text { Upper } \\
\text { Bound }\end{array}$ \\
\hline \multicolumn{7}{|l|}{ Request information } \\
\hline Yes & 1,063 & 2.05 & 2.29 & 7.02E-02 & 1.91 & 2.19 \\
\hline No & 301 & 1.95 & 2.26 & .13 & 1.69 & 2.21 \\
\hline Total & 1,364 & 2.03 & 2.28 & $6.18 \mathrm{E}-02$ & 1.91 & 2.15 \\
\hline Number of Nights Stay & \multicolumn{2}{|c|}{ Sum of Squares } & $d f$ & Mean Square & $F$ & $p$ \\
\hline \multirow{3}{*}{$\begin{array}{l}\text { Between groups } \\
\text { Within groups } \\
\text { Total }\end{array}$} & \multirow{2}{*}{\multicolumn{2}{|c|}{$\begin{array}{r}2.376 \\
7,089.509\end{array}$}} & 1 & 2.376 & .456 & .499 \\
\hline & & & 1362 & 5.205 & & \\
\hline & \multicolumn{2}{|c|}{$7,091.885$} & 1363 & & & \\
\hline
\end{tabular}

Note: $A N O V A=$ analysis of variance. 


\section{References}

Andereck, K. L., \& Caldwell, L. L. (1994). Variable selection tourism market segmentation models. Journal of Travel Research, 33, 40-46.

Bauwens, M. (1995). Knowledge transfer theory and practice. The Information Advisor, 7(6), 1-8.

December, J. (1996). Units of analysis for Internet communication. Journal of Communication, 46, 14-38.

Furr, H. L., \& Bonn, M. A. (1998). The Internet and the hospitality marketing professional. Journal of Applied Hospitality Management, 1, 60-69.

Jacoby, J., Hoyer, W., \& Brief, A. (1992). Consumer psychology. In M. D. Dunnette \& L. M. Hough (Eds.), Handbook of industrial and organizational psychology (Vol. 3, 2nd ed., pp. 378-441). Palo Alto, CA: Consulting Psychologists Press.

Kasavana, M. L., Knutson, B. J., \& Polonowski, S. J. (1998). Netlurking: The future of hospitality Internet marketing. Journal of Hospitality and Leisure Marketing, 5, 31-44.

Kotler, P. (1991). Marketing management: Analysis planning and control (7th ed.). Englewood Cliffs, NJ: Prentice Hall.

Morris, M., \& Ogan, C. (1996). The Internet as mass medium. Journal of Communication, 46, 39-50.

Morrison, A. M. (1989). Hospitality and travel marketing. Albany, NY: Delmar.

Morrison, A. M., Pearce, P. L., Moscardo, G., Nadkami, N., \& O’Leary, J. T. (1996). Specialist accommodation: Definition, market served, and roles in tourism development. Journal of Travel Research, 35(1), 18-25.

Murphy, I. P. (1997, September 23). On-line ads effective? Who knows for sure? Marketing Research, pp. 1,5 .

Newhagen, J. E., \& Rafaeli, S. (1996). Why communication researchers should study the Internet: A dialogue. Journal of Communication, 46, 4-13.

Peterson, R. A., Balasubramanian, S., \& Bronnenberg, B. J. (1997). Exploring the implications of the Internet for consumer marketing. Journal of the Academy of Marketing Science, 24, 329-346. 
Schonland, A. M., \& Williams, P. W. (1996). Using the Internet for travel and tourism survey research: Experiences from the net traveler survey. Journal of Travel Research, 35(2), 81-87.

Sutton, R. I. (1989). Reactions of nonparticipants as additional rather than missing data: Opportunities for organizational research. Human Relations, 42,423-439.

Uysal, M., Fesenmaier, D. R., \& O’Leary, J. T. (1994). Geographic and season variation in the concentration of travel in the United States. Journal of Travel Research, 32(3), 61-64.

Walle, A. H. (1996). Tourism and the Internet: Opportunities for direct marketing. Journal of Travel Research, 35(1), 72-77.

Williams, P. W., Bascombe, P., Brenner, N, \& Green, D. (1996). Using the Internet for tourism research: "Information highway or dirt road"? Journal of Travel Research, 34(4), 63-70. 